\title{
Liquid chemiluminescent DNA pull-down assay to measure nuclear receptor-DNA binding in solution
}

\author{
Toshiharu Iwasaki, Wataru Miyazaki, Nana Rokutanda, and \\ Noriyuki Koibuchi \\ Gunma University Graduate School of Medicine, Maebashi, Gunma, Japan
}

BioTechniques 45:445-448 (October 2008)

doi 10.2144/000112915

Electrophoretic mobility shift assays (EMSAs) are commonly used to investigate proteinDNA binding in vitro. However, EMSA can generate considerable amounts of undesirable waste, particularly when toxic compounds are examined. We therefore developed a novel in vitro protein-DNA binding assay called liquid chemiluminescent DNA pull-down assay, which is based on solution hybridization between digoxigenin-labeled DNA and glutathione S-transferase (GST)-fused DNA binding protein bound to glutathione-Sepharose beads.

\section{INTRODUCTION}

Protein-DNA interaction in vitro is usually detected by electrophoretic mobility shift assays (EMSAs) $(1,2)$ that require radioisotopically labeled DNA and autoradiographic visualization (Figure 1A). These lengthy processes generate radioactive and toxic waste. Furthermore, detection of weak binding is difficult because proteinDNA complexes must migrate through polyacrylamide gels. A nonradioisotopebased EMSA system has been developed to avoid radioactive contamination (3). However, gel electrophoresis and transfer of separated DNA-protein complex to a membrane are required, which also generates waste. The disposal of large volumes of toxic and/or radioactive waste can be problematic, particularly when toxic compounds are examined.

We recently demonstrated that several polychlorinated biphenyl (PCB) congeners known to be endocrine disrupting chemicals suppress transcription through thyroid hormone receptor (TR), a ligand-regulated transcription factor, by dissociating TR from thyroid hormone response element (TRE) $(4,5)$. Because thyroid hormone plays a critical role in brain development and because perinatal exposure to $\mathrm{PCB}$ and/or dioxin may produce abnormal brain development similar to that seen in hypothyroid mammals $(6,7)$, we started screening a series of known PCB and dioxin congeners with chemical structures similar to that of PCB (8) for their ability to disrupt TR binding to TRE. PCB has 209 congeners, whereas dioxin has 210 (8). Furthermore, various other chemicals also have similar structures to PCB/dioxins (9). Since EMSA might not be an ideal or appropriate technique for such massive screening for the reasons stated above, we developed a novel liquid chemiluminescent DNA pull-down assay that uses a digoxigenin (DIG)-labeled DNA with a nuclear hormone response element (NRE) and glutathione $S$-transferase (GST)-nuclear receptor (NR) fusion protein (Figure 1B, 1). The protein complex and DNA are hybridized in solution and are detected without electrophoresis by a chemiluminescent reaction. This procedure is much more rapid than EMSA, and it generates far less waste.

Double-stranded oligonucleotides (100 ng) containing an NRE are labeled with DIG using DIG Gel Shift Kit (Roche Diagnostics, Basel, Switzerland) to a final concentration of $4 \mathrm{ng} / \mu \mathrm{L}$ of the labeled oligonucleotide. Liquid chemiluminescent DNA pull-down assays can be performed using either DIG-labeled or biotinylated DNA. We purify the GST-fusion protein using glutathioneSepharose 4B (GE Healthcare, Little Chalfont, UK) according to the manufacturer's instruction. In brief, GST-fusion protein is produced from a GST expression vector in Escherichia coli (5). The $1 \mathrm{~mL}$ glutathione-Sepharose $4 \mathrm{~B}$ is incubated with 3-4 mL sonicated bacteria containing the GST-fusion protein in 30-40 mL GST binding buffer $[75 \mathrm{mM}$ $\mathrm{KCl}, 50 \mathrm{mM} \mathrm{NaCl}, 1 \mathrm{mM}$ EDTA, $1 \mathrm{mM}$ dithiothreitol (DTT), $10 \%$ glycerol, $0.1 \%$ Triton X-100] for $4-16 \mathrm{~h}$ at $4^{\circ} \mathrm{C}$. During this step, GST-fusion protein is bound to glutathione-Sepharose beads. After washing the beads with GST binding buffer, the GST-fusion protein bound to glutathione-Sepharose beads are stored in GST binding buffer at $4^{\circ} \mathrm{C}$.

GST-fused NR ( 2 $\mu \mathrm{g} /$ reaction) bound to glutathione-Sepharose 4B beads is incubated with $10-20 \mathrm{fmol}$ DIG-labeled double-stranded DNA fragments in protein-DNA binding buffer from the kit [20 mM Hepes, $\mathrm{pH}$ 7.6, $1 \mathrm{mM}$ EDTA, $10 \mathrm{mM}\left(\mathrm{NH}_{4}\right)_{2} \mathrm{SO}_{4}, 1$ mM DTT, $0.2 \%(\mathrm{w} / \mathrm{v}$ ) Tween $20,30 \mathrm{mM}$ $\mathrm{KCl}$ ] in a final volume of $20 \mu \mathrm{L}$ for $1 \mathrm{~h}$ at room temperature to bind GST-fused NR on beads to DIG-labeled DNA. GST-fused proteins bound to DNA on beads are washed three times with $\sim 1$ $\mathrm{mL}$ washing buffer from the kit $[0.1 \mathrm{M}$ maleic acid, $0.15 \mathrm{M} \mathrm{NaCl}, \mathrm{pH} 7.5,0.3 \%$ (v/v) Tween 20] with or without ligand, then the beads are incubated in $\sim 500$ $\mu \mathrm{L}$ blocking solution $[10 \%(\mathrm{w} / \mathrm{v}) 10 \times$ blocking solution in maleic acid buffer: $0.1 \mathrm{M}$ maleic acid, $0.15 \mathrm{M} \mathrm{NaCl}$; adjust with $\mathrm{NaOH}$ to $\mathrm{pH}$ 7.5] from the kit for 30 min before incubation with anti-DIG antibody Fab-fragments conjugated with $75 \mathrm{mU} / \mathrm{mL}$ alkaline phosphatase for $30 \mathrm{~min}$. Beads are washed twice with washing buffer from the kit before incubation in detection buffer $(0.1 \mathrm{M}$ Tris-HCl, $0.1 \mathrm{M} \mathrm{NaCl}, \mathrm{pH} 9.5$ ) from the kit for 2-5 min. Beads are transferred to 96-well plates and incubated with $1 \mu \mathrm{g} /$ $\mathrm{mL}$ chemiluminescent substrate disodium 3-(4-methoxyspiro \{1,2-dioxetane-3, $2^{\prime}$ (5'-chloro) tricyclo [3.3.1.13,7]decan $\}$ 4-yl) phenyl phosphate (CSPD) working solution for $5 \mathrm{~min}$ at room temperature followed by $10 \mathrm{~min}$ at $37^{\circ} \mathrm{C}$ to enhance CSPD chemiluminescent reaction. Light emission was measured using a MicroLumatPlus LB 96V luminometer (Berthold Technologies, Bad Wildbad, Germany). Our procedure produces results in about one-tenth of the time, while generating about $10 \%$ of the waste associated with EMSA. Using this 


\section{Lasergene $\mathbf{8 . 0}$}

A

EMSA

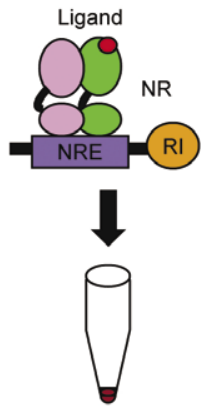

Incubation
in $1.5 \mathrm{ml}$ tube $(1 \mathrm{~h})$

\section{Meet the needs of today} with a solution for tomorrow.

The Lasergene 8.0 suite of sequence analysis tools bridges the gap between conventional and next generation sequencing - allowing you to use the same software for analysis and visualization of both sequencing methods.

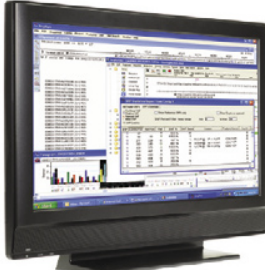

Featuring the highly effective functionality of previous versions, Lasergene 8.0 also

includes many new capabilities.

New Lasergene 8.0 benefits your research with:

- Simplified primer design and virtual cloning, thanks to the added primer designing capabilities in SeqBuilder

- Faster and easier SNP detection and analysis for your specific project needs

- Ideal for Next Generation platforms; can be used with SegMan NGen for enhanced analysis and visualization of data

Discover how Lasergene 8.0 is bridging the gap between the needs of today and the promise of tomorrow. Contact us for a free 30-day fully functional trial version.

\section{QLasergenen}

DNASTAR, Inc - Madison, WI, USA www.dnastar.com

Toll free: 866.511 .5090

US $608.258 .7420 \cdot$ UK 0.808 .234 .1643 DNA binding buffer.
B

Liquid chemiluminescent DNA pull-down assay
1) GST-NR + NRE

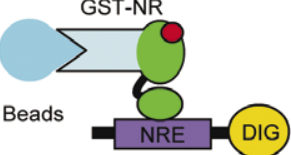

I

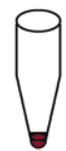

Incubation

in $1.5 \mathrm{ml}$ tube $(1 \mathrm{~h})$

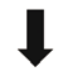

Chemiluminescent reaction on the beads (1 h)

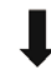

Measure light activities with a luminometer (1 min)
2) GST-cofactor

$+\mathrm{NR}+\mathrm{NRE}$

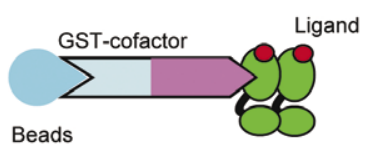

NR

Incubation

in $1.5 \mathrm{ml}$ tube $(16 \mathrm{~h})$
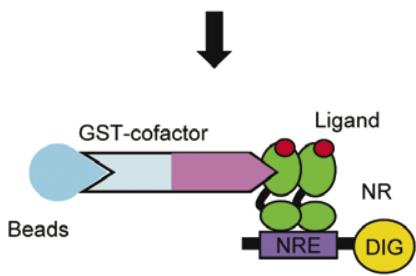

Incubation

in $1.5 \mathrm{ml}$ tube $(1 \mathrm{~h})$

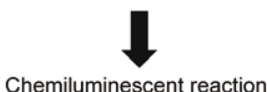

on the beads (1 h)

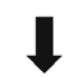

Measure light activities with a luminometer (1 min)

Figure 1. Assay methods to detect DNA-protein binding. (A) Representation of electrophoretic mobility shift assay (EMSA). Radioisotope (RI)-labeled DNA and in vitro-translated nuclear receptor (NR) are incubated, and then the mixture is resolved by electrophoresis on polyacrylamide gels, dried, and visualized by autoradiography. (B) Representation of liquid chemiluminescent DNA pull-down assay. 1) Detection of NR-DNA binding. A glutathione $S$-transferase (GST)-fused NR (GST-NR) bound to glutathione-Sepharose beads is incubated with a digoxigenin (DIG)-labeled double-stranded DNA fragment containing a nuclear hormone response element (NRE) in protein-DNA binding buffer. After extensive washing, protein-DNA binding on beads is detected using anti-DIG antibody conjugated to alkaline phosphatase, which is measured by a chemiluminescent reaction using a luminometer. 2) Detection of cofactor-NR-DNA binding. A GST-fused cofactor bound to glutathione-Sepharose beads is incubated with in vitro-translated NR in protein-protein binding buffer for $1 \mathrm{~h}$ at room temperature or for $16 \mathrm{~h}$ at $4^{\circ} \mathrm{C}$. After washing, the DIG-labeled double-stranded DNA fragment containing NRE is incubated with cofactor-NR complexes on beads in protein-DNA binding buffer for $1 \mathrm{~h}$ at room temperature in protein-

procedure, we are able to screen a large number of compounds within $4 \mathrm{~h}$.

We previously showed that PCB suppresses TR-mediated transcription $(4,5)$, which is a critical step for normal brain development (10,11). Using EMSA, we showed that PCB suppression of TR-mediated transcription is due to partial dissociation of TR from TRE (5) Based on this finding, we tested our novel assay using GST-TR $\beta 1$ and DIG-labeled TRE (Figure 2A). GST did not interact with DIG-TRE (Figure 2A, columns 1 and 2), whereas GST-TR $\beta 1$ showed binding in the absence of ligand (Figure 2A, column 3). Adding triiodothyronine 


\section{Benchmarks}

A
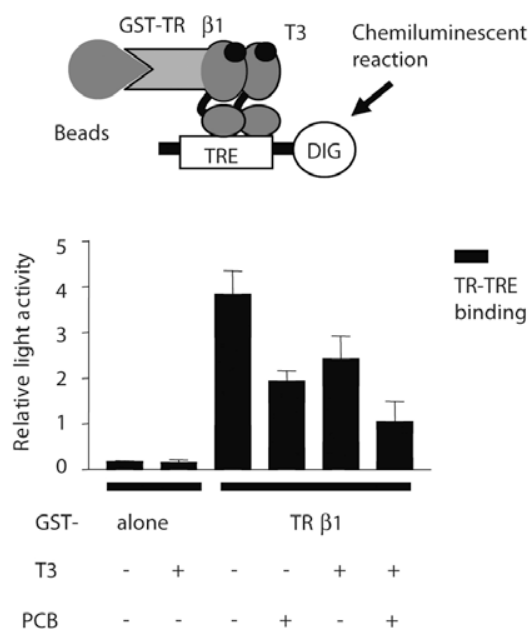

B
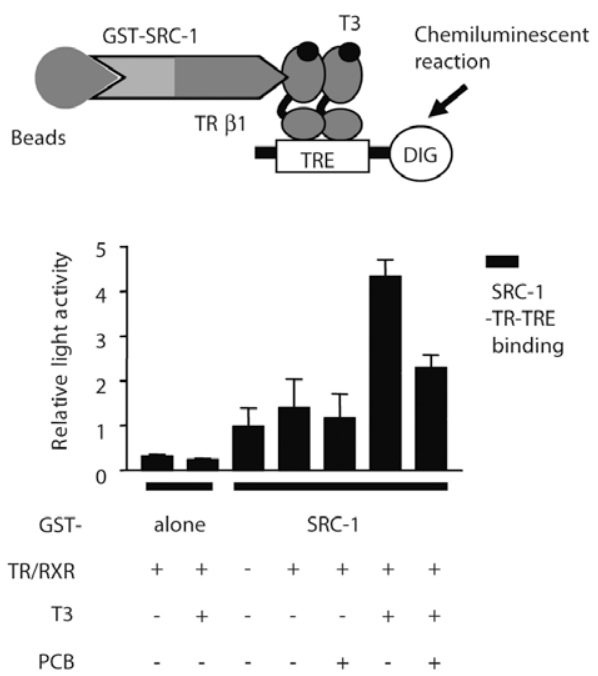

C
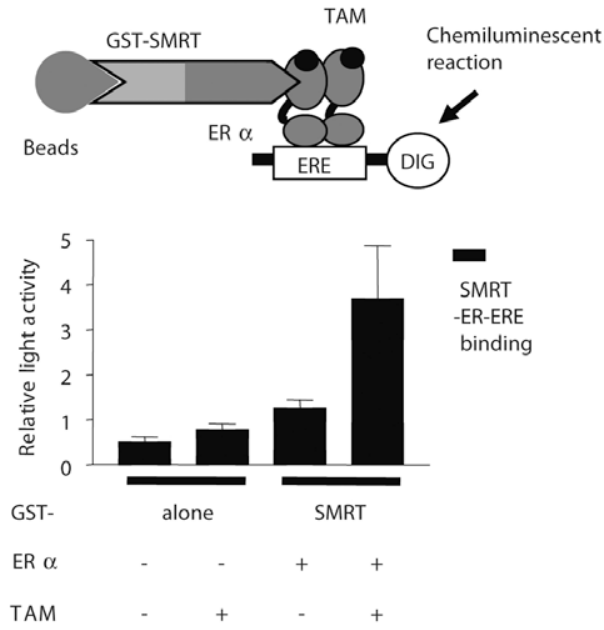

Figure 2. Examples of the liquid chemiluminescent DNA pull-down assay. (A-C) Light emission was measured from the liquid chemiluminescent DNA pull-down assay to indicate binding. The histograms indicate relative light emission. Data are shown as means \pm SEM. (A) Effect of polychlorinated biphenyl (PCB) on thyroid hormone receptor $\beta 1$ (TR $\beta 1$ )-thyroid hormone response element (TRE) binding. Glutathione $S$-transferase (GST)-TR $\beta 1$ was incubated with digoxigenin (DIG)-labeled TRE with or without T3 and/or PCB. (B) Effect of PCB on steroid receptor coactivator-1 (SRC-1)-TR 31 -TRE binding. GST-SRC-1 was incubated with in vitro-translated TR $\beta 1$ and retinoid X receptor (RXR), then SRC-1-TR $\beta 1 / R X R$ complex was incubated with DIG-labeled TRE with or without T3 and/or PCB for $1 \mathrm{~h}$ at room temperature. (C) Effect of tamoxifen on silent mediator for retinoid and thyroid hormone (SMRT)-estrogen receptor $\alpha$ $(\mathrm{ER} \alpha)$-estrogen response element (ERE) binding. GST-SMRT was incubated with ER $\alpha$, then SMRT-ER $\alpha$ complex was incubated with DIG-labeled ERE with or without $17 \beta$-estradiol (E2) and/or tamoxifen (TAM). After detection reaction, light emission was measured to indicate binding as described above. Data are shown as means \pm SEM.

(T3) reduced binding (Figure 2A, column 5), and PCB dissociated TR from TRE in the absence or presence of T3 (Figure 2A, columns 4 and 6). These are consistent with the findings observed with EMSA (5).

Since NR-mediated transcription is not exerted directly by NR itself but by cofactors, we further developed the assay to detect cofactor-NR-NRE binding (Figure 1B, 2). In vitrotranslated NR is prepared using rabbit reticulocyte lysate (Promega, Madison, WI, USA) according to the manufacturer's instruction using $1 \mu \mathrm{g}$ expression plasmid in a final reaction volume of 50 $\mu \mathrm{L}$. GST-fused cofactor ( $2 \mu \mathrm{g} /$ reaction) on glutathione-Sepharose beads is incubated with $5 \mu \mathrm{L}$ in vitro-translated $\mathrm{NR}$ in protein-protein binding buffer (20 mM HEPES, pH 7.4, 50 mM NaCl, 75 $\mathrm{mM} \mathrm{KCl,} 1 \mathrm{mM}$ EDTA, $0.05 \%$ Triton $\mathrm{X}-100,10 \%$ glycerol, $1 \mathrm{mM}$ DTT) in a final volume of $1 \mathrm{~mL}$ for $1 \mathrm{~h}$ at room temperature or $16 \mathrm{~h}$ at $4^{\circ} \mathrm{C}$. Thereafter, 10-20 fmol DIG-labeled double-stranded DNA fragments containing an NRE are incubated with the GST-cofactor-NR complex on glutathione-Sepharose beads in protein-DNA binding buffer from the kit for $1 \mathrm{~h}$ at room temperature. During this incubation, GST-fused cofactor on the beads binds to in vitro-translated NR that could bind DIG-labeled DNA. The order of incubation for protein-DNA binding and protein-protein binding can be changed. Subsequent steps are the same as described above in the assay to detect NR-NRE binding.

We reported that $T R \beta 1 /$ retinoid $X$ receptor (RXR) binds to TRE in the absence or presence of T3 (5). Adding T3 caused TR $\beta 1 /$ RXR complexes to bind steroid receptor coactivator-1 (SRC-1) in a T3-dependent manner (5) (Figure 2B, columns 4 and 6). PCBs do not affect TR $\beta 1-S R C-1$ binding (5). However, adding PCB dissociated about half of the TR $\beta 1 / R X R-S R C-1$ complex from TRE/ RXR (Figure 2B, column 7). This result is comparable to those of functional data $(4,5)$ and EMSA $(5)$.

We also used estrogen receptor $\alpha$ $(\mathrm{ER} \alpha)$ and estrogen response element (ERE) (Figure 2C). In the absence of ligand, ER $\alpha$ bound to ERE. The interaction between ER $\alpha$ and silent mediator for retinoid and thyroid hormone (SMRT) was limited (Figure 2C, column 3 ). Adding tamoxifen induced $\mathrm{ER} \alpha$ and SMRT binding as reported (Figure 2C, column 4). These results are comparable to those obtained using GST pull-down assays (2).

Our novel technique generates simultaneous results for large numbers of compounds, consistent with findings obtained with EMSA, but within $4 \mathrm{~h}$ and with minimal waste and opportunity for contamination. In addition, this assay can detect subtle binding that could become dissociated during migration through acrylamide gels. This technique can be used to examine the binding between most DNA binding proteins and DNA in vitro. We have also applied this technique to RNA-protein binding and protein-protein binding (data not shown). The results showed that our assay was versatile and sensitive enough to discriminate binding, which can be difficult to detect by EMSA or GST pulldown assays.

\section{ACKNOWLEDGMENTS}

This work was supported by a Grantin-Aid for Scientific Research on Priority Areas (17659281 to N.K. and T.I., and 17510039 to T.I. and N.K.) from the Japanese Ministry of Education, Science, Sports and Culture and Long-Range 
Research Initiative (LRI) (2005NT2 to N.K. and 2006NT0204 to T.I.) from Japan Chemical Industry Association (JCIA).

\section{COMPETING INTERESTS STATEMENTS}

T.I. was previously employed by Eli Lilly and Company. The other authors have no competing interests to declare.

\section{REFERENCES}

1. Sen, R. and D. Baltimore. 1986. Multiple nuclear factors interact with the immunoglobulin enhancer sequences. Cell 46:705-716

2. Smith, C.L., Z. Nawaz, and B.W. O'Malley. 1997. Coactivator and corepressor regulation of the agonist/antagonist activity of the mixed antiestrogen, 4-hydroxytamoxifen. Mol. Endocrinol. 11:657-666.

3. Herlt, M., H.P. Schwarz, R. Neumann, and H.J. Eggers. 1988. Detection of DNA-protein binding in western blots by phosphorus-labeled and biotinylated DNA probes. BioTechniques 6:324-331.

4. Iwasaki, T., W. Miyazaki, A. Takeshita, Y. Kuroda, and N. Koibuchi. 2002. Polychlorinated biphenyls suppress thyroid hormone-induced transactivation. Biochem. Biophys. Res. Commun. 299:384-388

5. Miyazaki, W., T. Iwasaki, A. Takeshiata, Y. Kuroda, and N. Koibuchi. 2004 Polychlorinated biphenyls suppress thyroid hormone receptor-mediated transcription through a novel mechanism. J. Biol. Chem. 279:18195-18202.

6. Jacobson, J.L. and S.W. Jacobson. 1997. Evidence for PCBs as neurodevelopmental toxicants in humans. Neurotoxicology 18:415424.

7. McKinney, J.D. 1989. Multifunctional receptor model for dioxin and related compound toxic action: possible thyroid hormone-responsive effector-linked site. Environ. Health Perspect. 82:323-336

8. Tilson, H.A. and P.R. Kodavanti. 1997. Neurochemical effects of polychlorinated biphenyls: an overview and identification of research needs. Neurotoxicology 18:727-743.

9. Safe, S.H. 1998. Development validation and problems with the toxic equivalency factor approach for risk assessment of dioxins and related compounds. J. Anim. Sci. 76:134-141.
10. Koibuchi, N. and W.W. Chin. 2000. Thyroid hormone action and brain development. Trends Endocrinol. Metab. 11:123-128.

11. Rabie, A., C. Favre, M.C. Clavel, and J. Legrand. 1977. Effects of thyroid dysfunction on the development of the rat cerebellum, with special reference to cell death within the internal granular layer. Brain Res. 120:521-531.

Received 22 January 2008; accepted 16 June 2008.

Address correspondence to Toshiharu Iwasaki, Department of Integrative Physiology, Division of Biological Regulation, Gunma University Graduate School of Medicine, 3-39-22 Showa-machi, Maebashi, Gunma 371-8511, Japan. e-mail:tiwasaki@med.gunma-u.ac.jp

To purchase reprints of this article, contact Reprints@BioTechniques.com

\section{It just clicked!}

\section{3-clicks away from pure DNA}
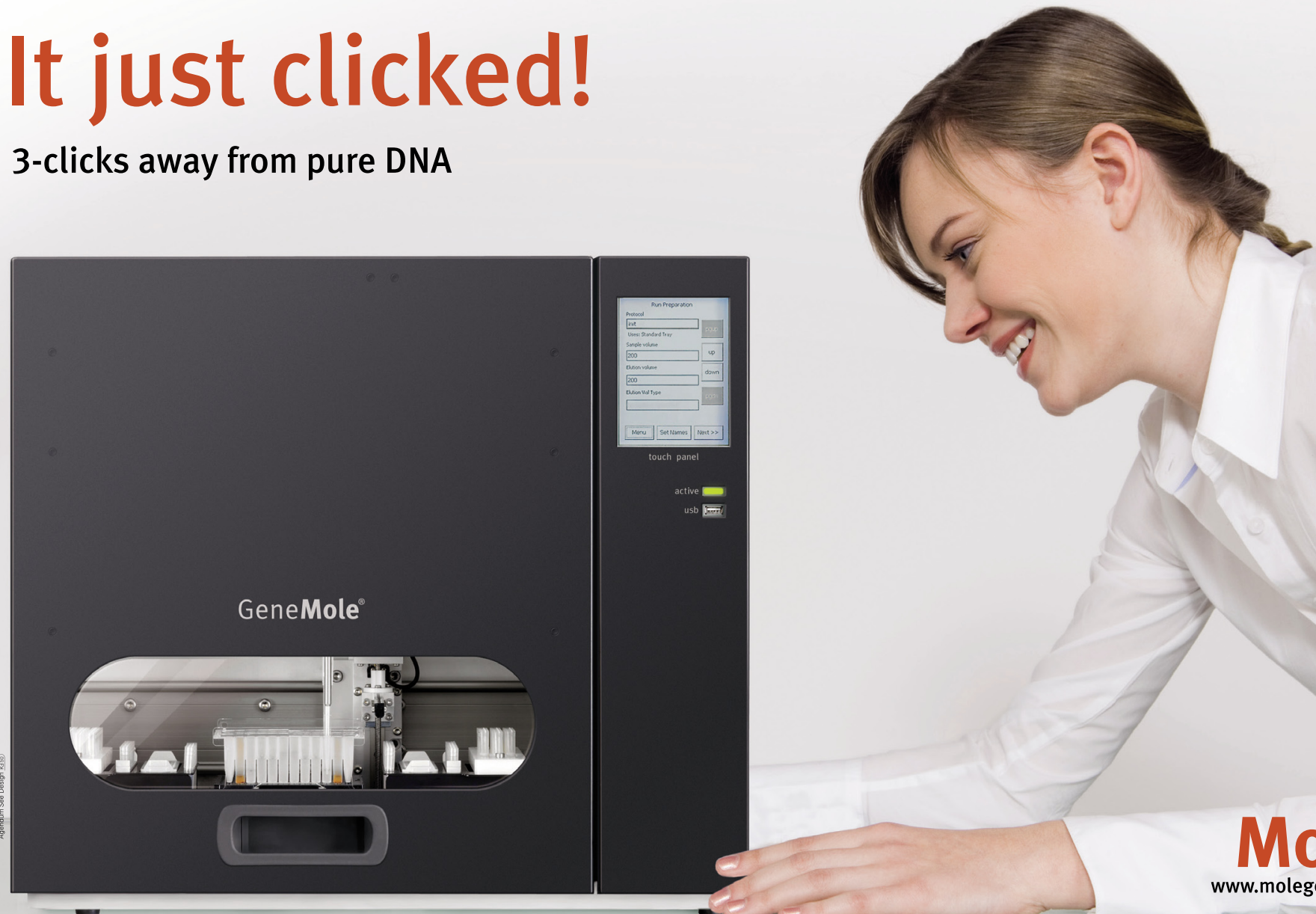